\title{
Knowledge and Attitudes of Primary Wing School Teachers toward Dental Trauma and its Management in Qassim, Kingdom of Saudi Arabia
}

\author{
Khalaf M Almutairi ${ }^{1}$, Mohammad A Baseer ${ }^{2}$, Navin A Ingle ${ }^{3}$, Jamal A Alsanea ${ }^{4}$, Sultan Binalrimal ${ }^{5}$, Ghada Alotaibi ${ }^{6}$
}

\begin{abstract}
Aim: To assess the knowledge and attitudes of primary wing schoolteachers toward dental trauma and its management in Qassim, Kingdom of Saudi Arabia.

Materials and methods: A cross-sectional survey was carried out among primary wing schoolteachers using a self-administered questionnaire. The questionnaire comprised 27 questions having three sections: personal and professional profile of the respondents and training on first aid, attitude of teachers toward dental trauma, and knowledge with regard to dental trauma. Data were analyzed using SPSS 21.

Results: In total, 400 primary wing schoolteachers participated in this study. Most of the respondents have received first aid training. The majority responded that dental trauma emergency management must be among the educational priorities for teachers. The teacher intervention in school dental injuries does play a significant role in traumatized tooth. The majority of the participants inappropriately answered the questions assessing the knowledge of management of dental trauma.

Conclusion: The knowledge of primary wing schoolteachers regarding the management of dental trauma is poor. Educational courses to improve the knowledge and awareness are essential.

Keywords: Attitude, Dental trauma, Knowledge, Management, Primary wing schoolteacher.

Journal of Oral Health and Community Dentistry (2020): 10.5005/jp-journals-10062-0066
\end{abstract}

\section{INTRODUCTION}

Dental traumatic injuries occur most commonly among children., ${ }^{1,2}$ The prevalence of dental trauma ranges from $4.9 \%$ to $37 \%$ in different countries, and half of the children experience dental trauma. ${ }^{3}$ The prevalence of dental trauma is considered high during infancy to adolescence, and boys are usually more prone than girls due to their hyperactivity. The peak incidence for dental trauma reported in boys is usually between 2-4 and 9-10 years of age and in girls is usually between 2 years and 3 years of age. ${ }^{4}$ Furthermore, due to active involvement of boys in sport and games, prevalence of dental trauma is three times more when compared with girls. ${ }^{5}$

Dental trauma can cause both functional and esthetic problems which may affect the child psychologically and physiologically. ${ }^{6}$ The consequences of dental trauma range from a simple minor tooth fracture to an extremely invasive injury affecting the tooth and supporting structures. ${ }^{7}$ Intrusion of primary wing teeth is one of the common and critical problems as it may affect the erupting permanent teeth. ${ }^{8}$ The teeth most frequently affected are maxillary central incisor (37\%), followed by mandibular central incisor (18\%), mandibular lateral incisor (6\%), and maxillary lateral incisor (3\%). ${ }^{9}$

Falls and collisions are the frequent reasons of dental trauma, followed by sports activities such as soccer and cycling. ${ }^{10}$ Dental trauma occurs at home or at school, and parents, caregivers, and teachers, respectively, are usually present at the time of injury. It is reported that half of dental trauma occur in schools. ${ }^{11,12}$ Among the different types of dental trauma, avulsion causes the maximum functional and esthetic impairment due to its poor prognosis. ${ }^{13}$ Hence, proper management of dental trauma is mandatory for reducing the impact on the oral health and quality of life of the children. ${ }^{14}$

\footnotetext{
1,3 Department of Dental Public Health, Riyadh Elm University, Riyadh, Kingdom of Saudi Arabia

2,4 Department of Preventive Dentistry, Riyadh Elm University, Riyadh, Kingdom of Saudi Arabia

${ }^{5,6}$ Department of Restorative Dentistry, Riyadh Elm University, Riyadh, Kingdom of Saudi Arabia
}

Corresponding Author: Khalaf M Almutairi, Department of Dental Public Health, Riyadh Elm University, Riyadh, Kingdom of Saudi Arabia, Phone: +966 553148788, e-mail: Khalaf89.m@gmail.com

How to cite this article: Almutairi KM, Baseer MA, Ingle NA, et al. Knowledge and Attitudes of Primary Wing School Teachers toward Dental Trauma and its Management in Qassim, Kingdom of Saudi Arabia. J Oral Health Comm Dent 2020;14(1):22-26.

Source of support: Nil

Conflict of interest: None

Dental trauma frequently occurs at school and its surroundings; thus, schoolteachers play an influential role in their management and thus can improve their prognosis. ${ }^{15}$ Therefore, teachers' knowledge about management of dental trauma such as the storage media, tetanus vaccine, and other first aid measures can be vital for both saving the teeth and maintaining the child's general health. ${ }^{14}$ Failure to follow the correct first aid measures to manage such injury may result in serious problems extending to the permanent dentition. Therefore, proper technical knowledge and experience is essential in order to correctly deal with such injuries. ${ }^{16}$

As children spend their maximum awake time in school, being engaged in sports and games, the knowledge and attitude of schoolteachers regarding management of dental trauma is 
crucial to ensure good prognosis. Therefore, it is essential that schoolteachers should have the basic knowledge about dental trauma and the treatment protocol for such injuries. Studies among schoolteachers revealed that they had insufficient knowledge on the management of dental trauma. ${ }^{13,17-19}$ The aim of this study was to assess the knowledge and attitudes of primary wing schoolteachers toward dental trauma and its management in Qassim, Kingdom of Saudi Arabia.

\section{Materials and Methods}

In the present cross-sectional survey, primary wing schoolteachers were selected through random sampling. A previously validated, anonymous, closed-ended self-administered questionnaire ${ }^{20}$ was circulated among the schoolteachers. The 27-item questionnaire comprised three sections: the first section comprised information on the personal and professional demographic profile of the respondents and training on first aid. The second section had questions related to attitude of teachers toward dental trauma. The third section comprised questions assessing participants' knowledge with regard to dental trauma.

The required ethical clearance was obtained from the institutional ethical clearance committee to carry out the study. Permission for executing the survey was obtained from the administration of the respective schools. Confidentiality and anonymity was assured. Before the data collection, the purpose and the methodology of this survey was explained to the teachers. Teachers were invited to voluntarily participate in the study. The standardized questionnaire was completed by teachers in school. In total, 350 schoolteachers were included. Completing the questionnaire was considered consent for inclusion in the study.

The subjects present and willing to participate in the survey were included in the study. The subjects reluctant to participate and incomplete questionnaires were excluded.

Statistical package for the social sciences (SPSS) Version 21 was used for data analysis. A descriptive analysis in the form of frequencies and percentages was performed to present the overview of the findings.

\section{Results}

The majority of the respondents were females (72\%), working in government schools (94\%), and with graduate education level

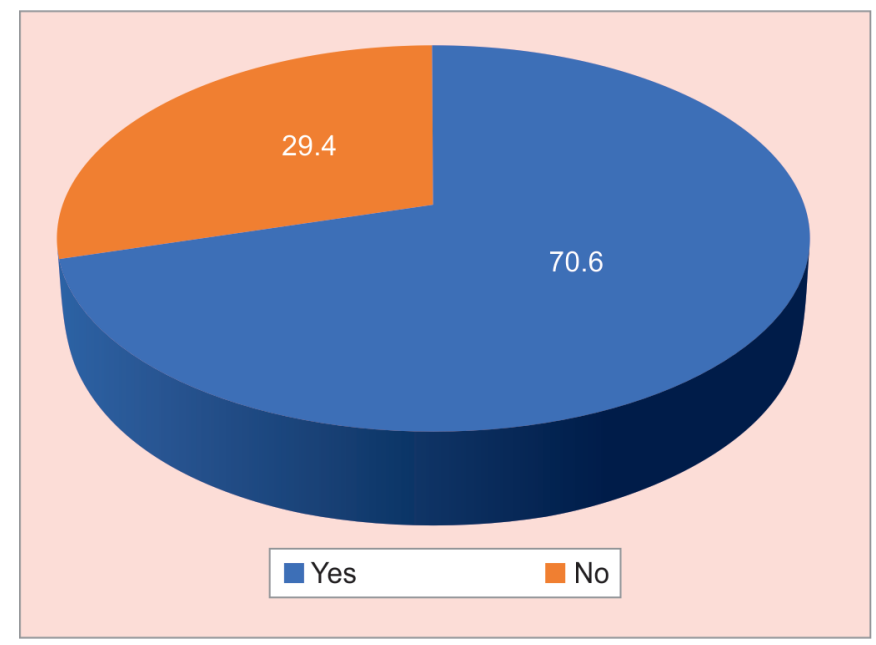

Fig. 1: First aid training
(75.1\%). The distribution of respondents by age group and years of teaching is shown in Table 1. Most of the respondents have received first aid training (70.6\%; Fig. 1), and approximately half the respondents have witnessed dental trauma accident (50.6\%; Fig. 2).

Figure 3 shows the attitude of the respondents. The majority of the respondents agree that time consciousness for emergency management plays a vital role in improving the prognosis of traumatized tooth (90.0\%); dental trauma emergency management must be made as the educational priorities for teachers (68.5\%); teacher intervention in school dental injuries may play a pivotal role $(78.6 \%)$; wearing a mouth guard should be mandatory in all contact sports (56.1\%); and having short pertinent educational experiences, educators can definitely provide better assistance while dealing with traumatic dental injuries (86.5\%). On the contrary, most of the respondents disagree that a teacher is not responsible for posttraumatic dental injuries (52.2\%), a tooth after avulsion will be lost definitely, so there is no need for treatment $(71.4 \%)$, and dental trauma emergency is not an emergency situation (67.9\%).

Table 2 shows the knowledge of the respondents. The majority of the respondents answered aptly for the question "Do you think it is important to seek emergency management for dental trauma?"

Table 1: Demographic

\begin{tabular}{llcc}
\hline & & Frequency $(n)$ & Percentage \\
\hline Gender & Male & 98 & 28 \\
School type & Female & 252 & 72 \\
& Government & 329 & 94 \\
Age group & Private & 21 & 6 \\
& $<30$ years & 43 & 12.3 \\
& 31-40 years & 153 & 43.7 \\
& 41-50 years & 126 & 36 \\
Education level & D50 years & 28 & 8 \\
& Diploma & 71 & 20.3 \\
& Graduate & 263 & 75.1 \\
Years of teaching & Postgraduate & 16 & 4.6 \\
& $<5$ years & 60 & 17.1 \\
& 5-10 years & 96 & 27.4 \\
& 11-20 years & 95 & 27.1 \\
& $>$ 20 years & 99 & 28.3 \\
\hline
\end{tabular}

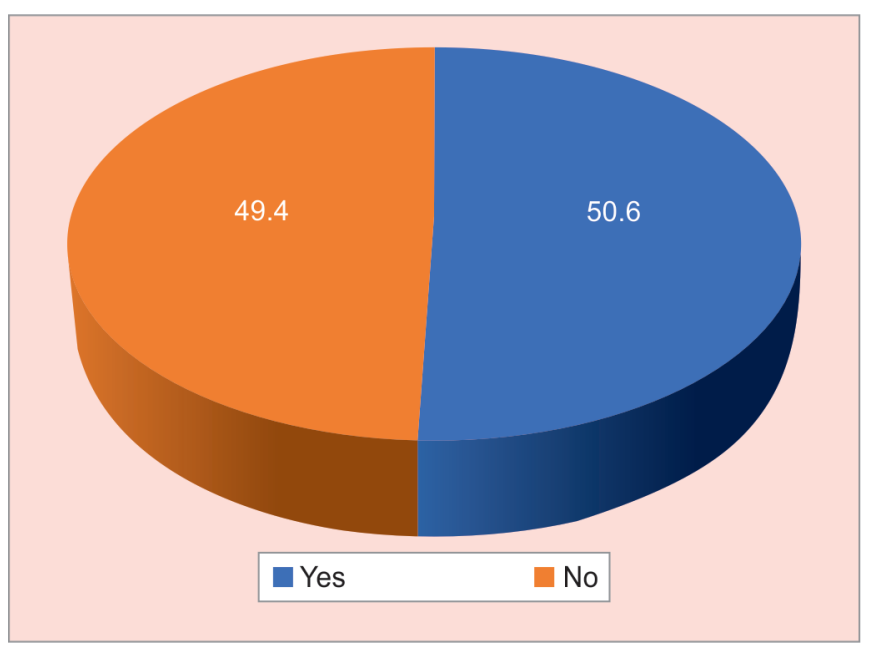

Fig. 2: Witnessed dental trauma accident 


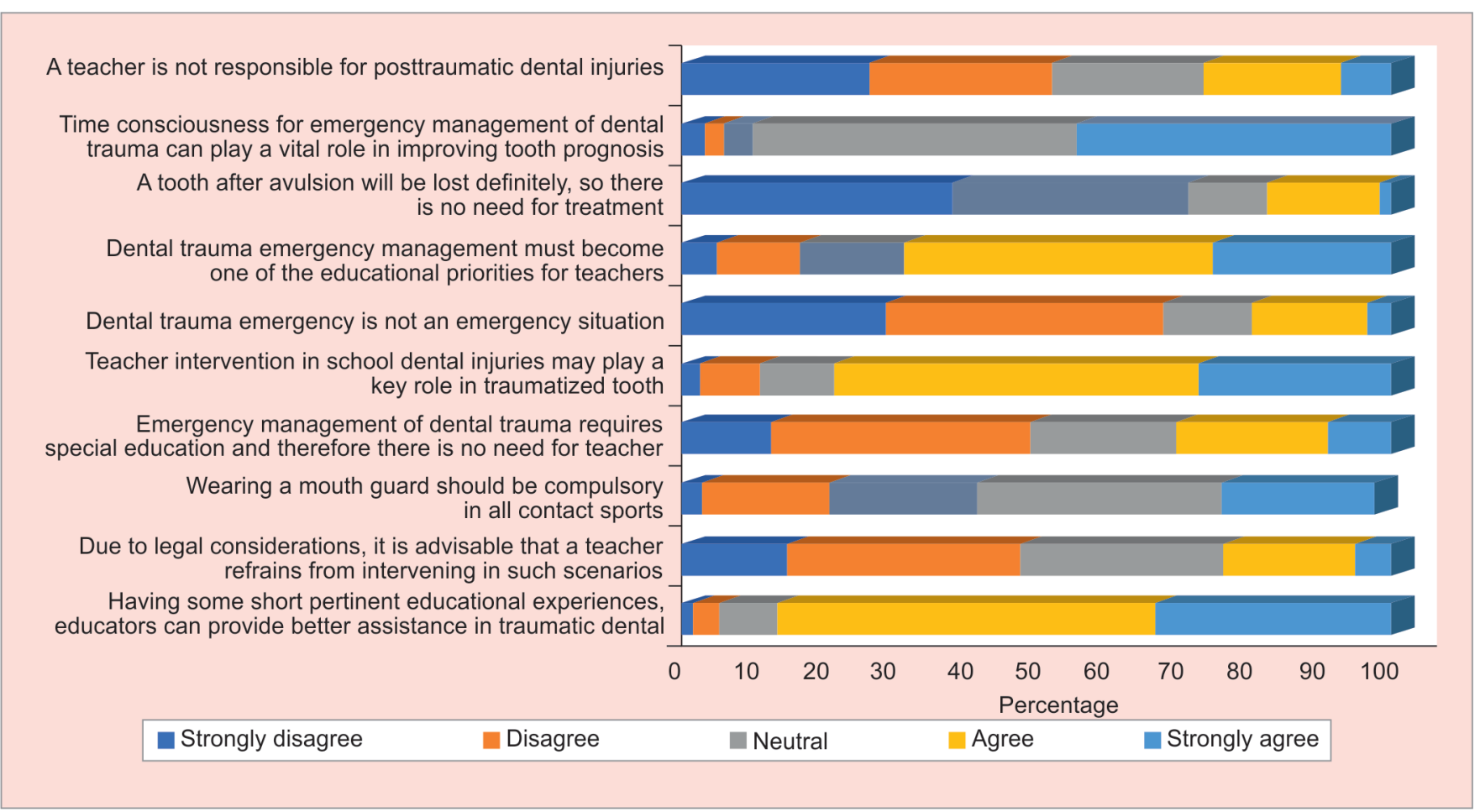

Fig. 3: Attitude of the respondents

Table 2: Knowledge of the respondents

\begin{tabular}{|c|c|c|c|c|}
\hline & $\begin{array}{l}\text { Appropriate } \\
\text { answer }\end{array}$ & $\begin{array}{l}\text { Inappropriate } \\
\text { answer }\end{array}$ & $\begin{array}{l}\text { Appropriate } \\
\text { answer }\end{array}$ & $\begin{array}{l}\text { Inappropriate } \\
\text { answer }\end{array}$ \\
\hline Questionnaire items & $n$ & Percentage & $n$ & Percentage \\
\hline $\begin{array}{l}\text { A 9-year-old child is hit on the face by a ball and fractures two } \\
\text { anterior teeth. Are the affected teeth: }\end{array}$ & 247 & 70.6 & 103 & 29.4 \\
\hline Which of the following actions do you consider most adequate? & 177 & 50.6 & 173 & 49.4 \\
\hline $\begin{array}{l}\text { At school, a } 12 \text {-year-old child falls down the stairs and hits his/her } \\
\text { mouth on the floor. One of his/her top front teeth was knocked out } \\
\text { of the mouth. What would be the first thing you do? }\end{array}$ & 91 & 26 & 259 & 74 \\
\hline $\begin{array}{l}\text { If you decide to reimplant the tooth back in its place, but it had } \\
\text { fallen on the floor, what would you do? }\end{array}$ & 13 & 3.7 & 337 & 96.3 \\
\hline $\begin{array}{l}\text { If you chose to wash the tooth, which solution would you use to } \\
\text { wash it? }\end{array}$ & 131 & 37.4 & 219 & 62.6 \\
\hline $\begin{array}{l}\text { If you do not reimplant the tooth, how would you transport it to the } \\
\text { dentist? }\end{array}$ & 19 & 5.4 & 331 & 94.6 \\
\hline $\begin{array}{l}\text { How urgently do you think that you should seek professional help } \\
\text { if a permanent tooth is knocked out? }\end{array}$ & 96 & 27.4 & 254 & 72.6 \\
\hline $\begin{array}{l}\text { Do you think it is important to seek emergency management for } \\
\text { dental trauma? }\end{array}$ & 9 & 2.6 & 341 & 97.4 \\
\hline
\end{tabular}

(82.3\%). Over half the respondents answered aptly for the questions "A 9-year-old child is hit on the face by a ball and fractures two anterior teeth. Are the affected teeth:" (59.4\%) and "Which of the following actions do you consider most adequate?" (56.2\%). The majority of the respondents answered inappropriately for the remaining questions regarding knowledge.

\section{Discussion}

Approximately half of the children in school suffer from dental trauma. ${ }^{21}$ During recreational activities at school, children have an increased likelihood of dental trauma. This indicates investigation of schoolteachers' attitude and knowledge regarding dental trauma and treatment approaches. ${ }^{22,23}$ Attitude and knowledge of the schoolteachers is vital in ensuring better prognosis of their treatment as they are more likely to be around during the incident of trauma. ${ }^{24}$ Several studies have reported that majority of the participants had experienced dental trauma at schools and mentioned that the knowledge regarding dental trauma management is essential. ${ }^{25}$ Therefore, this study aimed to investigate the attitude and knowledge in primary wing schoolteachers regarding dental trauma and management. 
In this study, $70.6 \%$ of teachers had received first aid training on dental trauma, which was much higher than the previous studies. ${ }^{20,26}$ A total of $50.6 \%$ teachers witnessed some type of accident similar to an earlier study. ${ }^{26}$ However, another study reported a much lower percentage. ${ }^{23}$ The majority of the teachers had dissatisfying knowledge about dental trauma and management. On the contrary, a study reported that half the teachers had dissatisfying knowledge about dental trauma and emergency protocols. ${ }^{26}$ Only $26.5 \%$ of the teachers answered the question correctly that most adequate solution for washing an avulsed tooth is filtered water or saline solution. Moreover, only $15.9 \%$ correctly stated milk, the oral cavity, or filtered water as the adequate solution for sending the avulsed tooth to the dentist. These findings were similar to previous studies also. ${ }^{27,28}$

The majority of teachers $(82.3 \%)$ were in favor of seeking immediate professional help in response to the question regarding the urgency of seeking professional help. Similar result was obtained from a study conducted among Indian schoolteachers. ${ }^{29}$ Female teachers reported significantly higher knowledge regarding dental trauma and its management when compared with male teachers, which is also in line with the previous study. This could be attributed to the fact that women have more contact with children in outdoor environments and most of them are mothers. ${ }^{26}$ The majority $(72.8 \%)$ of the schoolteacher were in favor of receiving short training on how to manage dental trauma cases, as they themselves were not satisfied with their knowledge regarding emergency management of dental trauma, and this finding was similar to a previous study. ${ }^{29}$

In this study, the optimum knowledge about management of dental trauma among primary wing schoolteachers is insufficient. Schoolteachers should have the basic knowledge regarding the recognition and management of dental emergencies. Programs to update teachers' knowledge about management of dental trauma should be incorporated in teachers training program. One important step that can be considered to improve the knowledge level among schoolteachers is identification of the target group in the teacher's community, i.e., class teachers, physical education teachers, life sciences teachers, and the principal as they directly come in contact with schoolchildren. ${ }^{30}$ One of the limitations of this study is that the findings are limited to one city and may not be representative of the national picture.

\section{ConcLusion}

This study highlighted the fact that the primary wing schoolteachers lack knowledge regarding management of dental trauma. There is a need for greater awareness to improve teachers' attitude and knowledge related to management of dental trauma in children. The findings should be addressed and teachers need to be informed about the significant role they could play in the management of dental trauma. Further research is recommended to determine the most effective method to improve the knowledge of primary wing schoolteachers.

\section{Ethical Approval}

The approval of the study and ethical clearance was obtained from Research Center of Riyadh Elm University, Kingdom of Saudi Arabia. All participants signed the pconsents attached to the questionnaire.

\section{ACKnOWLedgment}

Authors would like to acknowledge Talal Alshammari for the contribution in the data collection.

\section{References}

1. Obied M, Al-Maiman S, Al-Jumah G, et al., Knowledge and Awareness of Primary wing School Teachers Towards Emergency Management of Dental Trauma; A Survey Based Study in Schools of Riyadh, KSA. Vol. 17; 2018.

2. Nikam AP, Kathariya MD, Chopra K, et al. Knowledge and attitude of parents/caretakers toward management of avulsed tooth in maharashtrian population: a questionnaire method. J Int Oral Health 2014;6(5):1.

3. Attarzadeh $\mathrm{H}$, Kebriaei F, Sadri L, et al. Knowledge and attitudes of elementary schoolteachers on dental trauma and its management in Yazd, Iran. J Dentistry 2017;18(3):212.

4. Nirwan M, Syed AA, Chaturvedi S, et al. Awareness in primary wing school teachers regarding traumatic dental injuries in children and their emergency management: a survey in South Jaipur. Int J Clini Pediat Dent 2016;9(1):62. DOI: 10.5005/jp-journals-10005-1335.

5. Fountain SB, Camp JH. Traumatic injuries. Pathways of the pulp. Chicago: Mosby; 1994. pp. 436-485.

6. Singh M, Ingle NA, Kaur N, et al. Evaluation of knowledge and attitude of school teachers about emergency management of traumatic dental injury. J Int Soc Prevent Commu Dent 2015;5(2):108. DOI: 10.4103/2231-0762.155735.

7. Chan AW, Wong TK, Cheung GS. Lay knowledge of physical education teachers about the emergency management of dental trauma in Hong Kong. Dent Traumato 2001;17(2):77-85. DOI: 10.1034/j.16009657.2001.017002077.x.

8. Mendoza-Mendoza A, Iglesias-Linares A, Yañez-Vico RM, et al. Prevalence and complications of trauma to the primary wing dentition in a subpopulation of Spanish children in Southern Europe. Dental Traumat 2015;31(2):144-149. DOI: 10.1111/edt.12147.

9. Marwah N. Textbook of Pediatric Dentistry. Jaypee Brothers, Medical Publishers Pvt. Limited; 2018.

10. Knowlton R, Kracher CM, Smith WS, Sports-related dental injuries and sports dentistry. Accessed February 2016, 2.

11. Mohandas U, Chandan G. Knowledge, attitude and practice in emergency management of dental injury among physical education teachers: a survey in Bangalore urban schools. J Indian Soc Pedodo Prev Dent 2009;27(4):242. DOI: 10.4103/0970-4388.57660.

12. Sae-Lim V, Lim LP. Dental trauma management awareness of Singapore pre-school teachers. Dent Traumat 2001;17(2):71-76. DOI: 10.1034/j.1600-9657.2001.017002071.x.

13. Togoo RA, Yaseen SM, Al-Shehri DA, et al. Knowledge and attitude of Saudi Arabian school teachers with regards to emergency management of dental trauma. Int J Clin Dent Sci 2011;2(2).

14. Ilma de Souza Cortes M, Marcenes W, Sheiham A. Impact of traumatic injuries to the permanent teeth on the oral health-related quality of life in 12-14-year-old children. Commu Dent Oral Epidemiol 2002;30(3):193-198. DOI: 10.1034/j.1600-0528.2002.300305.x.

15. Pacheco LF, Filho PFG, Letra A, et al. Evaluation of the knowledge of the treatment of avulsions in elementary school teachers in Rio de Janeiro, Brazil. Dent Traumatol 2003;19(2):76-78. DOI: 10.1034/j.16009657.2003.00109.x.

16. Antunes LAA, Pretti RT, Lima LF, et al. Traumatic dental injury in primary wing teeth: knowledge and management in Brazilian preschool teachers. J Dent Oral Hygie 2015;7(2):9-15. DOI: 10.5897/ JDOH2014.0135.

17. Vuleti M, Škariči J, Batinjan G, et al. A retrospective study on traumatic dental and soft-tissue injuries in preschool children in Zagreb, Croatia. Bosnian J Basic Med Sci 2014;14(1):12. DOI: 10.17305/bjbms.2014. 2283.

18. Abuelqomsan MAS, Aljeaidi ZA, Albalawi AO, et al. Knowledge about management of avulsed tooth among primary wing school teachers of Riyadh. SRM J Res Dent Sci 2017;8(1):5.

19. Alsadhan SA, Alsayari NF, Abuabat MF. Teachers' knowledge concerning dental trauma and its management in primary wing schools in Riyadh, Saudi Arabia. Int Dent J 2018;68(5):306-313. DOI: 10.1111/idj.12385. 
20. Al-Obaida M. Knowledge and management of traumatic dental injuries in a group of Saudi primary wing schools teachers. Dent Traumatol 2010;26(4):338-341. DOI: 10.1111/j.1600-9657.2010. 00894.x.

21. Glendor U. Aetiology and risk factors related to traumatic dental injuries-a review of the literature. Dent Traumatol 2009;25(1):19-31. DOI: 10.1111/j.1600-9657.2008.00694.x.

22. Faus-Damia M, Alegre-Domingo T, Faus-Matoses I, et al. Traumatic dental injuries among schoolchildren in Valencia, Spain. Med Oral Patol Oral Cir Bucal 2011;16(2):e292-e295. DOI: 10.4317/medoral.16. e292.

23. Arikan V, Sönmez H. Knowledge level of primary wing school teachers regarding traumatic dental injuries and their emergency management before and after receiving an informative leaflet. Dent Traumatol 2012;28(2):101-107. DOI: 10.1111/j.1600-9657.2011. 01042.x.

24. Walker A, Brenchley J. It'sa knockout: survey of the management of avulsed teeth. Accid Emerg Nurs 2000;8(2):66-70. DOI: 10.1054/ aaen.1999.0115.
25. Hashim R. Physicians' knowledge and experience regarding the management of avulsed teeth in United Arab Emirates. J Int Dent Med Res 2012;5(2):91-95.

26. Pithon MM, Santos RLd, Magalhães PHB, et al. Brazilian primary wing school teachers' knowledge about immediate management of dental trauma. Dent Press J Orthod 2014;19(5):110-115. DOI: 10.1590/21769451.19.5.110-115.oar.

27. Tzigkounakis V, Merglová V. Attitude of pilsen primary wing school teachers in dental traumas. Dent Traumatol 2008;24(5):528-531. DOI: 10.1111/j.1600-9657.2008.00645.x.

28. Feldens EG, Feldens CA, Kramer PF, et al. Understanding school teacher's knowledge regarding dental trauma: a basis for future interventions. Dent Traumatol 2010;26(2):158-163. DOI: 10.1111/j.16009657.2009.00863.x.

29. Kaul R, Jain P, Saha N, et al. Evaluation of knowledge, awareness, and attitude toward emergency dental trauma management among the school teachers of Kolkata. Indian J Dent Res 2017;28(6):595. DOI: 10.4103/ijdr.IJDR_118_17.

30. Sai Sankar A, Sreedevi E, Suresh Babu M, et al. School teacher's knowledge regarding dental health. Indian J Dent Sci 2013;5(2). 